Analysing Organisations 


\section{ANALYSING ORGANISATIONS}

\section{Third Edition}

Sandra Dawson

The Judge Institute of Management Studies

University of Cambridge

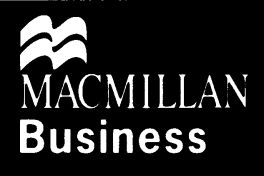


(c) Sandra Dawson, 1986, 1992, 1996

Softcover reprint of the hardcover 3rd edition 1996 978-0-333-66094-2

All rights reserved. No reproduction, copy or transmission of this publication may be made without written permission.

No paragraph of this publication may be reproduced, copied or transmitted save with written permission or in accordance with the provisions of the Copyright, Designs and Patents Act 1988, or under the terms of any licence permitting limited copying issued by the Copyright Licensing Agency, 90 Tottenham Court Road, London W1P 9HE.

Any person who does any unauthorised act in relation to this publication may be liable to criminal prosecution and civil claims for damages.

First edition 1986

Reprinted 1983, 1989

Second edition 1992

Reprinted 1993 (twice), 1994

Third edition 1996

Published by

MACMILLAN PRESS LTD

Houndmills, Basingstoke, Hampshire RG21 6XS

and London

Companies and representatives

throughout the world

ISBN 978-0-333-66095-9 ISBN 978-1-349-24846-9 (eBook)

DOI 10.1007/978-1-349-24846-9

A catalogue record for this book is available from the British Library.

$\begin{array}{llllllllll}10 & 9 & 8 & 7 & 6 & 5 & 4 & 3 & 2 & 1\end{array}$

$\begin{array}{llllllllll}05 & 04 & 03 & 02 & 01 & 00 & 99 & 98 & 97 & 96\end{array}$ 
To Henry, Hannah, Rebecca and Tom 


\section{Contents}

List of Figures $\quad \mathrm{xi}$

List of Tables $\quad$ xiii

Preface to the First Edition $\quad \mathrm{xv}$

Preface to the Second Edition xvii

Preface to the Third Edition xviii

Acknowledgements $\quad \mathrm{xix}$

Introduction $\quad \mathbf{x x i}$

Definition and Characteristics xxii

The Elco Case xxiii

Main Themes of Analysis xxvi

Review Questions xxviii

PART ONE: A FRAMEWORK FOR

ORGANISATIONAL ANALYSIS

1 People: Attitudes, Motivation and Performance 3

1.1 The Formation of Attitudes to Work 4

1.2 Motivation 9

1.3 Individual Performance 17

1.4 Concluding Remarks 27

Review Questions 28 
Interest Groups, Objectives and Strategy

2.1 Interest Groups 29

2.2 Objectives and Goals 43

2.3 Defining Corporate Strategy 48

2.4 Introducing Organisational Performance 49 Review Questions 52

3 Technology: A Social Product 53

3.1 Technology: The Concept 54

3.2 Technology and Work Organisation 57

3.3 Technology, Organisation and Management Structure 65 Review Questions 76

4 The Environment: Opportunity and Constraint 77

4.1 'Environment': The Concept 78

4.2 Interactions across the Boundaries of Organisations:

A Practical Guide 79

4.3 Generating and Collecting Information about the Environment 83

4.4 Controlling and Reacting to the Environment 85

4.5 Analysing the Environment: Turbulence, Dominance, Interorganisational Relations and Networks 96

4.6 Concluding Remarks 107 Review Questions 107

5 Co-ordination and Control: Structure and Organisation Design 109

5.1 Addressing the Imperative for Co-ordination and Control

5.2 Defining Structure 111

5.3 Relationship Boundaries: Where to Draw the Lines 111

5.4 Formality of Relationships 118

5.5 Contingency Theory 123

5.6 The Analytical Validity and Practical Applicability of Contingency Theory 128

5.7 Concluding Remarks: And So ... What of Contingency Theory? 139

Review Questions 140

6 Culture: Creature or Creator?

141

6.1 The Place of Culture in Organisational Analysis

6.2 Different Perspectives on Corporate Culture 147

6.3 The Contribution of Culture to Performance 154

6.4 Concluding Remarks 162

Review Questions 162 


\section{PART TWO: PROCESSES IN ORGANISATIONS}

7

Power and Conflict 167

7.1 Defining Power Relationships 169

7.2 Conflict: A Precondition for the Exercise of Power 170

7.3 Opportunity for Change or Choice: A Precondition for the Exercise of Power 175

7.4 Sources of Constraint 175

7.5 Contact and Intention in Power Relationships 176

7.6 Zero Sum or Open Exchanges 177

7.7 Strategies to Secure and Increase Power 179

7.8 Concluding Remarks 186 Review Questions 187

8 Communication and Decision-making 188

8.1 Information and Communication 191

8.2 Communication Problems 193

8.3 Decision-making 201

8.4 A Typology of Decision-making Strategies 207

8.5 Concluding Remarks 213

Review Questions 214

Y Leadership 215

9.1 Defining Leadership 216

9.2 Approaches to Leadership 217

9.3 Transformational Leadership 227

9.4 Concluding Remarks 230

Review Questions 231

10 Managing Change: Implementation, Learning and

Creativity 232

10.1 A Model of Change in Organisations

233

10.2 Implementation and the Generation of Outcomes 240

10.3 The Limits of Rational Planning 251

10.4 Organisational Learning 253

10.5 Attitudes to Change 256

10.6 Evaluation and Feedback 260

10.7 Concluding Remarks: The Rational Model Revisited 261 Review Questions 263

11.1 Returning to the Main Themes 268

11.2 Summarising the Main Themes 268

Review Questions 269 
X Contents

Bibliography $\quad 270$

Name Index 288

Subject Index 293 


\section{List of Figures}

1.1 The formation of attitudes to work 5

1.2 Understanding individual job performance 18

1.3 Types of control on a job-holder 21

3.1 Functional workflows in a man-made fibre plant 55

3.2 The classification of technology, interdependence and co-ordination used by Thompson 72

4.1 Conceptualising the environment 82

4.2 Alternative strategies for coping with complexity and uncertainty in organisations 94

4.3 Practical guide to managing interactions across organisational boundaries 97

5.1 Elements of structure in organisations

112

5.2 Typical example of functional organisation 113

5.3 Typical example of product organisation 114

5.4 Typical example of matrix organisation 115

5.5 An empirical taxonomy of bureaucratic structures 123

5.6 Contingency theory: the problem areas 129

5.7 Measures of performance in an industrial company 136

6.1 A map of the corporate world: how culture may be revealed and created in organisations 143

6.2 Values attributed to the Japanese and their manifestation within the company 149

6.3 Illustrating the 'virtuous circle' which underlies Japan's industrial performance 156

8.1 The interaction of information, opinion and decisions in the development of detailed R \& D workplans 192

9.1 Approaches to leadership: how do you identify a successful leader? 217

9.2 Leadership functions: a long and incomplete list 218 
xii List of Figures

9.3 Contingency approaches to leadership 226

10.1 Change processes in organisations 236

10.2 Relating context, intentions, activities and outcomes:

a summary 247

11.1 Understanding performance 266 


\section{List of Tables}

1.1 Job requirements: basic elements of any job 19

2.1 Comparing unitary, pluralist and radical perspectives on interests and conflict

33

2.2 Characteristics historically associated with professional groups 34

2.3 Different relationships between professionals and managers

2.4 Assessing performance in organisations 51

3.1 Organisations as arenas for the transformation of inputs into outputs 54

3.2 Summary of the research and consultancy programme undertaken by the Tavistock Institute 58

3.3 The classification of production systems used by Woodward 66

3.4 Relationship between production system, information handling and behaviour in three factories 70

4.1 Ways to achieve greater dominance and control of the environment 86

4.2 Mechanistic and organic forms of organisation 89

5.1 Summary of practical and analytical problems with contingency theory 130

5.2 Meeting contingencies at different stages in product life-cycles

6.1 Back to basics: eight 'attributes of excellence' 150

7.1 Conditions for the overt and covert expression of conflict and exercise of power 171

7.2 Contact and intention in power relationships 177

7.3 Organisations as arenas for the exchange of valued resources 180

7.4 Examples of suppliers and recipients in exchanges of resources in an industrial organisation 181

7.5 Checklist for the analysis of power relationships in organisations 
8.1 Subject areas in which decision-making is important 189

8.2 Information and communication in organisations: general issues 194

8.3 Decision-making in organisations: general issues 202

8.4 A typology of decision-making strategies 208

10.1 Imperatives for a model of change in organisations 234

10.2 Implementation: general issues 241

10.3 Outcomes of activities and interactions in organisations: some examples 242

10.4 Actors and intentions: the Comset case 250

10.5 Single loop and double loop learning 254 


\section{Preface to the First Edition}

This book began as a series of lectures given at Imperial College to first-year students who were among the pioneers on the 'Dainton' four-year enhanced engineering courses. Each cohort of students, through their occasionally sharp and frequently thought-provoking injections of inspiration, questions and scepticism, has had an unwitting hand in the formation of the text. Its form and content have also been much influenced by contact, through research, consultancy and short courses, with managers and specialists who have proffered a different range of interests and criticisms to my analysis of organisations. The final product is intended for the successors of both these groups of people, that is, for those men and women who are now, or are intending to become, managers or specialists in organisations and who want, or are required, to become more expert in their analysis. I hope that the text will also be of interest to those who wish to make a more academic study of organisations. It may provide them with a different perspective on literature with which they are already familiar, and in particular the discussions in the last five chapters may introduce them to some new ideas. Its main attraction to students who wish to specialise in the study of organisations must, however, be that it attempts to bridge the gap between theory and practice in such a way as not to trivialise the former while establishing a framework for the latter.

This is an introductory text; it assumes no prior knowledge of organisational analysis. However, once the initial introduction is effected, the maintenance of the relationship between text and reader will demand careful thought and reflection from the latter. These demands derive, I hope, not from academic pretentiousness, which the reader may be assured is given little quarter by either the engineering students of Imperial College or young managers preoccupied with their immediate problems. In writing primarily for these audiences I hope I have fulfilled my side of the bargain and met the demands which the exercise has placed on me. I have certainly tried to avoid the unnecessary use of "jargon' and to provide a readable yet stimulating and rigorous guide to the nature 
of organisations and their analysis, drawing on illustrations and examples which I have encountered in the course of my industrial research and consultancy. The demands placed on the reader have not therefore been artificially created; they derive directly from the nature of the subject.

Organisations are highly complex, as are the people who inhabit them, and they should not, I believe, be oversimplified to the point where the impression is gained that they are easy systems to understand. To adopt a too simple approach is to trivialise the subject and to open the way for instantly appealing but ultimately misleading advice. I hope I have avoided the dangers of both trivialisation and unnecessary complexity. If I have, it is certainly in part due to the encouragement and constructive criticism I have received from my colleagues, friends and family to write, rewrite and often rewrite again. If I have failed, I regret that it is essentially my fault.

Many people have contributed significantly to my endeavours in writing this book. Thanks are due to Karen Legge, with whom I've worked closely in teaching this subject at Imperial College, to my other colleagues, my students and those in industry who have invited my consultancy and teaching or facilitated my research. The burden of typing the manuscript and coping with my idiosyncratic use of pen, paper, scissors and sellotape has fallen to several people, notably Kay Barnes, Joan Wright and, above all, Patricia Burge. My thanks to them all for their perseverance and kindness. I am also grateful for the help I have received from the staff at the publisher, particularly Jennifer Pegg.

Last, but certainly not least, I must record my debts to those at home. During the time in which this book has taken shape I have been the fortunate recipient of help and friendship from many people, particularly Elizabeth, Monika, Veronika, Petra, Giovanna and Lydia, and the staff of the Imperial College Nursery. In many different ways they have contributed to the creation of a home life in which a 'dual career' family with young children has, to give or take the odd crisis, flourished. My thanks to them all. My husband Henry, himself a manager, has in a sense acted as both target and inspiration for the book. He has responded to the challenge of my preoccupation with this text with a quiet generosity of ideas, comment and love which would be difficult to match. Perhaps I should also thank our children Hannah, Rebecca and Tom for the introductions they have given me to yet more organisations. For example, they have moved from nursery to school, they have joined drama and swimming clubs and together we have been reluctant but extensive explorers of a range of health service provision from routine outpatient clinics to intensive care units with almost all possible stops in between. But these incidental insights into organisations are of course nothing compared to living with those one loves. I can't claim they have always been patient with me, nor I with them, but I can be sure that we are all greatly relieved and not a little proud that 'the book' which has so often seemed to come before a trip to the swimming pool, the cinema or the zoo or a walk in the country has now really left my desk for the bookshop. Needless to say, though, another has already insinuated itself into the desk-top position! 


\section{Preface to the Second Edition}

This new edition of Analysing Organisations incorporates a large amount of new material while remaining true to its original purpose to be a rigorous guide to the nature of organisations and thereby to reveal things which are intellectually stimulating and practically relevant. There are two completely new chapters on culture and managing change and the sections on performance, structure and strategy have been substantially rewritten. These changes reflect significant developments in the theory and practice of organisational analysis and the interests and questions of the groups of MBA students whom I have been privileged to teach since the foundation of The Management School at Imperial College in 1987. Among the many to whom thanks are due are Karen Legge and Michael Brocklehurst, with whom I have worked closely in course design and all the managers, friends, colleagues and students who have shared in discussions which find reflection in the present text.

Lastly, and most importantly, there is the home team, Henry, Hannah, Rebecca and Tom, and all our friends who have joined our family in the five years that have elapsed between these two editions. The theme of managing conflict and paradox introduced in 1986 is further developed here. In rededicating this book to those I love, I remember with gratitude our shared efforts to balance the conflicting demands of work and play. 


\section{Preface to the Third Edition}

The third edition of Analysing Organisations includes one major new addition. Chapter 9 is devoted to leadership. It also addresses new issues which have come to the fore in recent years concerning the importance of networks and project teams, which have been facilitated, at least in part, by significant developments in Information Technology.

The other innovation in this edition is the inclusion of review questions at the end of each chapter. These can be used in private study by students as sample essay or examination questions, or as a basis for class or group discussions. Each question invites the reader to enter into some argument or debate. The answers will never be simple or uncontested, but to follow any justified line of argument should lead the student to destinations of greater clarity and understanding of the issues, and thereby, I hope, to a stronger base for practical action.

My motivation to write an accessible yet rigorous book, my debts to my colleagues and my students, and my dedication to those I love, remain unchanged. 


\section{Acknowledgements}

The author and publishers wish to thank the following who have kindly given permission for the use of copyright material:

Jossey Bass for material from Managing Organizational Performance by Michael Nash, published by Jossey Bass, 1983.

Administrative Science Quarterly for a diagram from 'An Empirical Taxonomy of Structures of Work Organizations' by D. S. Pugh, D. J. Hickson and C. R. Hinings, published in Administrative Science Quarterly, Vol. 14 (1) (March 1969) p. 123.

Every effort has been made to trace all the copyright-holders, but if any have been inadvertently overlooked the publishers will be pleased to make the necessary arrangements at the first opportunity. 


\section{Introduction}

\begin{tabular}{l} 
Definition and Characteristics xxii \\
The Elco Case xxiii \\
Main Themes of Analysis xxvi \\
Review Questions xxviii \\
\hline
\end{tabular}

Large-scale organisations play an important part in all our lives. They are the means by which goods and services are provided beyond the boundaries of an individual's or small group's capacity for self-sufficiency. Such provision may be made for profit through the framework of markets, or through some other more controlled framework of commercial or social provision. We are in contact with organisations, as employees, as customers, as clients and claimants, as suppliers, and as regulators. Organisations specialise in education, health care, the collection of rubbish, broadcasting radio and television programmes, supplying food and household requirements, and providing a range of other goods and services which are used by individuals, families, groups and other organisations. To understand how organisations have grown, how they function and the sources of stress and strain as well as efficiency within them, is an important area of knowledge. The aim of this book is to provide the reader with a framework for the analysis and understanding of organisations. The framework can be applied from different people's viewpoint but, as the choice of examples will show, the book has been written particularly with one large group of people in mind; its target is those who are, or who are likely to become, managers or technical specialists, who are as yet novices in the analysis of organisations, but who share an intellectual as well as a practical curiosity in discovering more about the subject.

In coming to the subject of organisation people often hope to be given instant recipes for personal and organisational success, and quickly become disillusioned when simple and specific answers and advice are not forthcoming. 
Therefore, let no such hopes be raised. This book will not prescribe particular actions or decisions, but it will offer something far more fundamental: understanding through analysis. Organisations are highly complex dynamic systems which emerge, develop or decline in diverse and changing technological, economic and social contexts. What is appropriate in one context will be totally inappropriate in another. What is advantageous to one person may be disadvantageous to another. The aim of this book is not to say categorically what actions should be taken but to describe and explain the interacting characteristics and processes that are found in organisations. On this basis readers will be better equipped to make their own decisions and play their own parts, which ultimately is what everyone has to do. The reader's curiosity and understanding will be fed more through illustrated examples and fairly simple forms of explanation than through detailed theoretical debates, although a number of theoretical alternatives will be introduced along the way.

\section{Definition and Characteristics}

Organisations are defined as collections of people joining together in some formal association in order to achieve group or individual objectives. At least one set of objectives for any organisation will relate to the production and output of specified goods and services to individuals, groups and other organisations.

The book is written in two parts. Part One deals with the nature and interrelationships between six key characteristics of any organisation. These are:

1. The people who are associated with it, their attitudes and values, their aspirations and experience of different types of work. The extent to which values, experience and objectives are shared varies, and is reflected in the formation of a variety of interest groups.

2. The strategies and tactics which together constitute the plans and policies for such areas as product range, price structure, personnel and technical innovation and change.

3. The technology or hardware of production processes, machinery, materials, products and information technology.

4. The environment to which an organisation's goods and services are supplied, from which its resources are obtained and which also provides the source of attempts to regulate its activities. This environment is constituted of individuals, groups, and most importantly other organisations, which have their own internal complexities and sources of stress and strength.

5. The structure of roles and relationships, revealed in organisation charts, job descriptions, the content and form of control systems and administrative procedures. Structure is a means to securing ends of co-ordination, control and communication. In some circumstances these ends can be achieved through the operation of a market or the creation of a network, rather than through 
a hierarchy. Consideration is thus also given to the invention, development, production and distribution of goods and services through networks of relationships, and markets as well as hierarchies.

6. The culture of the organisation, which is the shared values and beliefs which create distinctive patterns of thinking and feeling within organisations.

Part One provides the building blocks of the analysis through a discussion of these six characteristics and their interrelationships which are represented in the cover design of the book. As the reader becomes acquainted with the blocks it becomes clear that a static snapshot of characteristics is not sufficient and that change must be considered. This is the subject of Part Two, which deals with social processes in organisation with particular reference to the acquisition and exercise of power and influence, communication, decision-making, leadership and implementation, with a focus on the management of change, innovation and learning. The concluding chapter draws the threads together by revisiting the subject of understanding and managing performance, since this is the ultimate objective for the practitioner.

One of the first lessons which may be taken from this book is that it is foolish to accept the definition of problems which arise in organisations at their face value. The nature of the problem should be explored, it will be argued, using the analytical framework presented. The need to gain a realistic diagnosis of problems as a basis for deciding upon solutions and their implementation can be demonstrated through the example of Elco, an electrical engineering firm.

\section{The Elco Case}

Elco had reached an established and still growing position in the light electronics market through manufacturing fairly standard electrical equipment, which was largely sold as components to manufacturers of other products. On the retirement of the production director, his successor, Tom Wilson, was promoted from within the company on the basis of a good track record. He had started with the firm twelve years earlier as a graduate process engineer and had completed seven years' experience as a production manager. During his career with the firm he had been noted as conscientious and clever, someone who kept abreast of technical developments even when they were not directly relevant to his patch, who was 'fair' but not 'soft' in his dealings with people, and who was well able to stand the stresses associated with having to find short-term solutions to problems arising from the competing priorities of cost, quality and delivery. He also appeared well able to command respect from his subordinates and maintain good relations with his colleagues in other departments. And yet it seemed promotion went instantly to his head. No sooner did he sit in the production director's chair than he was reported to be unco-operative with all other departments and to be unable to delegate within his own 
department. The only person with whom he had a good working relationship was his personal assistant, Bill, whom he had appointed himself. Bill, a young graduate engineer with three years' industrial experience in another company, had taken his degree at the production director's own university.

Everyone's attention became focused on the problem of 'what to do about Tom'. The fact that he got on well with Bill only served to convince his critics that as well as being a megalomaniac he was also given to nepotism. Various suggestions were made about how to improve the situation and they all revolved around ways of 'changing' the impact that Tom was having on the company. One group of senior executives led by the Finance and Managing Directors, reluctant to throw away what had promised to be good board material, was thinking in terms of trying to change him through training. Their idea was to send him on a senior executive development programme which would be liberally peppered with hints on managing personal relations as well as some good solid material on delegation and co-operation. Another group, led by the Sales Director, was less charitable. They said they had always had reservations about his appointment and that now he had been revealed in his true colours, which were clearly not up to the calibre expected of a director, the board should cut their losses and 'let him go'. They proposed to offer Tom favourable terms if he left the company, but said that if he stayed, he would have to make a sideways move which they knew he would find unattractive. Fortunately, before either of these courses of action was undertaken the lone voice of the Technical Director suggested that as well as looking at the personal qualities of Tom, the board should also consider the context in which the company was now working.

Standing back from their immediate crisis and from their preoccupations with cash flow and market share, they began to realise where their piecemeal approach to process and product development had taken them. A paper from the Technical Director showed that recent technical and market developments meant that the fastest growing and certainly most profitable sectors of the company's production were no longer concerned with easy-to-make items which were hard to sell, but with hard-to-make items which were relatively easy to sell providing that the quality was up to specification. The newly appointed Production Director was in fact behaving perfectly rationally in the face of an inappropriate structure in which sales dictated delivery dates irrespective of production's views. Such a situation had been appropriate in the past since sales, facing a difficult task, had secured orders by promises of very quick deliveries which production had usually managed to meet. Now, however, quick delivery was not as important as high quality. Tom and Bill both appreciated this but were too impatient and preoccupied with their problems to discuss the implications with others. They also feared that discussions would be thwarted by the defence of vested interests which had derived strength and power, particularly for sales, from the 'old' situation. Rather than quarrel over every order, particularly as entrenched positions and interests were involved, Tom and Bill merely worked as a close-knit team, keeping all the information to 
themselves and 'fobbing off' sales with inaccurate predictions whenever they were tackled about delivery. They also began dealing directly with customers, cutting out sales and thus adding further fuel to the quarrel. As the crisis became acute, Tom and Bill became more distant from the rest of the organisation. There were still considerable technical teething problems with the new production processes and these were having an adverse effect on quality, the one thing which Tom and Bill knew the company could not afford. They were increasingly found at every hour of the day and night on the shop-floor, firefighting the problems as they arose.

One reason for the quality problems was inadequate training for the production and maintenance teams in the new technology. Both Tom and Bill were highly competent process engineers and so they became personally involved in solving the problems rather than developing an appropriate group of supervisors, operatives and craftsmen to handle day-to-day issues. Tom and Bill were so bound up with managing their hectic working hours on a short-term basis that they had not yet begun to consider how the production and maintenance workforce could be trained; indeed, they had not even raised the problem with the personnel and training department.

What appeared at first sight to be a problem with the personality and behaviour of one or two individuals subsequently showed itself to be a problem of far-reaching implications for the organisation. Had Tom been replaced, one can predict with confidence that his successor, who at the selection board appeared to be 'just the man', would probably soon have begun exhibiting similar behaviour. Alternatively, had he conformed to the expectations of the Sales Director, they would together have presided over a fall in market position, even if they had remained friends in the face of this adversity. This is not to say that Tom could not have behaved differently; he could. Had he voiced his concerns earlier, had he lobbied for support for a programme of organisational change, had he called upon other specialist functions earlier, then he could have helped to overcome the crisis sooner.

The particular problems manifest in Elco were a result of a combination of individual and organisational developments. Changes in the technology and markets inevitably created strains and stresses. Neither the changes themselves, nor their implications for marketing, personnel and production policy, were properly considered. Once the board began to appreciate that their problems were not simply ones of difficult personalities, they instituted a number of immediate developments.

The Technical Director chaired a strategic working party to plan the journey upon which they had already embarked, almost as a result of 'automatic pilot'. The group considered the extent to which they should try to boost their specialist markets and whether their old markets for 'easy-to-make' items had gone for ever. The Production and Personnel Directors gave careful consideration to recent process innovation and drew up a programme for training, manpower planning and an appropriate industrial relations structure. The whole board vowed that they would never let such changes 'creep up' on them again. 
What was wrong with their internal communications? Why did functions not speak to each other? Why did they not receive good intelligence information from their environment?

All these questions became subjects for serious discussion and resulted in a wealth of ideas and explicit proposals. But far from solving their problems these ideas and proposals seemed only to exacerbate them. Several pulled in conflicting directions, others appeared to have extremely difficult industrial relations implications, and yet others attacked vested interests. To make the diagnosis is clearly not enough to secure effective change. Decisions must be made in the context of different interests and the pursuit of associated shortand long-term objectives, or else they emerge from compromise or by default. Once made, decisions have to be implemented and evaluated.

The diagnosis of problems through an understanding of structure and process in organisations and the selections of solution is the subject matter of this book. Put simply, it aims to help people to know their organisation, to appreciate why particular characteristics and behaviours are exhibited, and to choose from a range of possible actions within the opportunities and constraints they have identified.

\section{Main Themes of Analysis}

As the analysis unfolds, the reader's attention will be drawn to a number of key themes, which have already been introduced in the Elco example. These will be stated here by way of introduction; the rationale for their inclusion will become clearer as they are elaborated in the book.

1. Interactive open systems. Organisations are interactive open systems. One can picture them as both generating and reacting to streams of interactive outcomes for each of their main parts: people, structure, culture, technology and strategy within the context of their environment. Change in one aspect inevitably means changes in others, and some of these changes will be unanticipated, and may be uncontrollable. Some of the changes will be internally generated; others will flow from interactions across boundaries with the environment. Openness to the environment means that organisations are both influenced by, and yet can have an influence on, their environment.

2. Uncertainty. Organisations are highly complex systems in which there is often a great deal of uncertainty. A lot of resources are always likely to be devoted to reducing and coping with uncertainties. Information, even if generated, will often not be shared between different parts of the organisation. Different participants operate with varying pictures of reality, and nearly all of them are incomplete.

3. An appropriate path through paradox. There is no one best way to act in organisations. The aim must always be to find an appropriate fit between a variety of elements such as technology, markets, history and the power and 
interests of the people involved. One must beware of jumping to unsubstantiated conclusions and always seek to examine assumptions both in diagnosis and prescription. But, even then, there are no simple solutions to problems; paradoxes are continually encountered and the reader will often be urged to heed two apparently contradictory pieces of advice: for example, to take advantage of specialisation and yet benefit from integration; to reap the benefits of giving subordinates discretion and yet maintain control; to consider the advantages of having clear lines of responsibility while also facilitating consultation and decision-making in cross-functional groups. Coping with uncertainty and contradiction are not things one does just once 'to get them out of the way'. They are an integral part of life in organisations, and individuals need to learn both how to deal with them and how they, as actors, contribute to their creation.

The creation of an appropriate balance or, as Pascale (1990) says, of 'managing on the edge' and not allowing strength on one side of a contradiction (e.g., specialisation) to reduce the other side (e.g., co-ordination) to insignificance, is an extremely important art in managing organisations.

4. Scarce resources. Resources are always more or less scarce, and none of the strategies chosen is likely to be without financial or social costs. The crucial question is to appreciate the value of the 'trade-offs' being made between costs and benefits, both in the short and the long term: 'there is no such thing as a free lunch'. It is always important to try to understand the menu and to attempt to estimate the full costs of benefits using both financial and non-financial indicators. In this way one is less likely to be surprised and to be faced with unanticipated consequences.

5. Conflicts and consensus between interest groups. People become involved with organisations in a variety of ways. The only common factor is that the organisation is seen as likely to provide things of value. What is of value to one group may be a subject of indifference or even hostility for another. Organisations are arenas in which different interest groups operate. Some degree of co-operation is usual; but so is an element of conflict. Emergent patterns of conflict and consensus not only reflect different interests but also the relative power and influence of groups to pursue those interests.

6. Opportunity, choice and constraint. People in organisations face varying degrees of constraints within which they have an element of choice. The relative balance between constraint and choice varies between groups and individuals and over time. What is seen as a constraint by one person may be seen as an opportunity by others. Moreover, today's constraints are largely the result of yesterday's choices. The juxtaposition of constraint and choice relates to an underlying issue of the relationship between an individual's freedom to act and think and her subjection to the influence of social structure and culture. This book takes a middle position in which everyone is more than an amalgamated reflection of the social influences to which they are exposed; but at the same time social influences are critically important in generating individual attitudes, values and actions. Technologies, environments, and 
indeed social structures and cultures are both the creators and creatures of people in organisations.

7. Levels and modes of analysis. A concern with the individual and social levels of analysis suggests one last general introductory comment. The activities which constitute life in organisations and the outcomes that arise can be analysed in terms of the different levels of the individual, group, organisation and society. For example, the introduction of a new payment system for maintenance workers in an oil refinery can be considered at the individual level in terms of its impact on a craftsman's motivation to stay in the job or his weekly spending habits. At a group level, the activities of the branch of the craft trade union in negotiating the deal are relevant, as is the effect of the new payment system on patterns of co-operation in working practices within and between groups. At an organisational level the impact of the new scheme on levels of refinery productivity is relevant, as are the changes in supervisory practices that accompany the new payment system. At a societal level one might consider the employment or redundancy effects of the new system and its relationship with trends in trade unionism generally. A further variation in styles of the analysis is between a static view based upon a cross-sectional snapshot, or a dynamic view based upon concepts of change. Rather than just looking at craft workers' responses to the new system at one time, their attitudes and behaviour in connection with payment systems before and after the change could be examined. Similarly, productivity could be considered over an extended time period.

This book is mainly concerned with analysis at the individual and organisational levels, although some consideration is given to the group. The treatment of the societal level is one-sided; considerable emphasis is given to prior social influences on individual attitudes, values and behaviour and to the economic and social context in which organisations operate. Less consideration is given to the reverse set of influences: that is, to the way the activities of individuals and the operations of organisations profoundly affect and indeed continually create conditions in the wider society and economy.

Even though the analysis is concentrated at the individual and organisational level, it is nonetheless important to recall the interrelationships between all four levels. The image of a set of Russian dolls in which the outer casing encapsulates dolls of decreasing size is a useful metaphor. Each doll is individually crafted but bears the shape of both the larger and the smaller ones; so, too, with individuals, groups, organisations and society.

\section{Review Questions}

1. Justify the importance of an understanding of conflict and balance in organisational analysis.

2. Describe circumstances in which you have encountered unexpected interactions 
between parts of an organisation with which you are familiar. What were the consequences of these interactions?

3. Take a problem which you have encountered in an organisation with which you are familiar. What do you understand to be its causes and what would you suggest could be done to address this problem? 